\title{
Implikasi RUU-BHP dan Perpres 77/2000
}

\author{
Sofian Effendi \\ Universitas Gajah Mada Yogyakarta
}

Essentially, national education is not a business sector to produce educated workers, and is not in the same category as mining industries, trade and services. National education is a government effort and all elements of nation to preserve national identity, to transfer norms and values, to sustain and develop the intellectual and cultural base of the society, to give inspiration and pride to citizens, and to promote dialogue for the respect of cultural and social diversity. Some of the main tasks of national education, especially basic and secondary education, is to transfer high values of nation, spirit of nationality, national identity, and to preserve and develop national cultures. These sacred tasks are those of govemment and are the responsibility of nation so that these are impossible to divert to investors of business sector of education services. Liberalization of high education and other sub-sectors of education must be conducted with a strong nationality.

Keywords: implication, education, liberalization, trade, services

$M$ enurut UUD 1945 salah tugas konstitusional Pemerintah adalah “... mencerdaskan kehidupan bangsa" dan karena itu Pemerintah berkewajiban memenuhi “ ... hak warganegara mendapatkan pendidikan." Mungkin untuk memenuhi kewajiban tersebut serta dalam rangka mempersiapkan sistem pendidikan nasional yang unggul dan bermutu, Pemerintah Indonesia melalui Perpres No. 77 tahun 2007 mengundang modal dalam dan luar negeri untuk berpartisipasi membangun sektor pendidikan agar mampu menghadapi globalisasi pendidikan. Melalui Perpres tersebut semua jenjang dan jenis pendidikan ditetapkan oleh Pemerintah sebagai bidang usaha yang terbuka bagi penanaman modal asing, dengan atau tanpa syarat. 2 kebijakan publik yang akan dan telah ditempuh dalam rangka melaksanakan Dua kebijakan tersebut adalah RUU BHP yang sedang digodok bersama oleh Pemerintah dan DPR-RI. Pemerintah dan DPR-RI juga saat ini sedang giat-giatnya menyelesaikan RUU Badan Hukum Pendidikan yang merupakan amanat UUNo. 20 tahun 2003 semua badan penyelenggara dan/atau satuan pendidikan formal berbentuk badan hukum.

Seluruh komunitas pendidikan perlu memberikan perhatian pada kebijakankebijakan tentang liberalisasi pendidikan yang ditetapkan dengan Perpres 77 tahun 2007 dan perietapan lembaga pendidikan formal sebagai badan hukum. Paling tidak ada 3 implikasi yang perlu diperhitungkan atas penetapan lembaga pendidikan formal sebagai Badan Hukum Pendidikan yaitu: (1) seberapa jauh RUU-BHP akan menimbulkan uniformisasi badan hukum untuk penyelenggara dan satuan pendidikan akan lebih bermanfaat bagi PTIS?; (2) Apakah BHP mengandung resiko intervensi Pemerintah yang akan menimbulkan ekonomi biaya tinggi dalam bidang pendidikan tinggi?, dan (3) Apa implikasi 
komodikasi dan liberalisasi pendidikan tinggi yang terbuka akibat pemberlakuan Perpres No. 77 tahun 2007? Ini lah tiga pertanyaan yang ingin saya jawab dalam tulisan ini.

\section{Amanat UU No. 20 tahun 2003}

Dalam konsideran UU No. 20 tahun 2003 tentang Sisdiknas Butir c. dirumuskan tantangan system pendidikan nasional sebagai berikut: "sistem pendidikan nasional harus mampu menjamin pemerataan kesempatan pendidikan, peningkatan mutu serta relevansi dan efisiensi manajemen pendidikan untuk menghadapi tantangan sesuaidengan tuntuan perubahan kehidupan lokal, nasional, dan global sehingga perlu dilakukan pembaharuan pendidikan secara terencana, terarah, dan berkesinambungan."

Untuk mencapai tujuan tersebut Pemerintah menetapkan perlunya penataan dan restrukturisasi sistem pendidikan pada tataran nasional sampai satuan pendidikan sehingga sistem tersebut memiliki kredibilitas yang tinggi dan akuntabel terhadap publik. Salah satu penataan untuk mencapai tujuan tersebut adalah menetapkan penyelenggara dan/atau satuan pendidikan formal harus berbentuk badan hukum pendidikan. UU No. 20 tahun 2003 tentang Sisdiknas menetapkan dalam Pasal 53 (1) s/d (4) sebagai berikut:

(1) Penyelengara dan/atau satuan pendidikan formal yang didirikan oleh Pemerintah dan masyarakat berbentuk badan hukum pendidikan.

(2) Badan hukum pendidikan sebagajmana dimaksudkan dalam ayat (1) berfungsi memberikan pelayanan kepada peserta didik.

(3) Badan hukum sebagaimana dimaksudkan dalam ayat (1) berprinsip nirlaba dan dapat mengelola dana secara mandiri untuk memajukan system pendidikan.

(4) Ketentuan tentang badan hukum pendidikan diatur dengan Undangundang tersendiri.

Agak berbeda dengan yang diamanatkan oleh UU, Pemerintah telah mengusulkan kepada DPR-RI bukan nama jenis badan hukum pendidikan tetapi suatu badan hukum khusus bernama Badan Hukum Pendidikan (BHP) sebagai ius constituendum dari badan hukum pendidikan yang diamanatkan oleh UU No. 20 tahun 2003 (Naskah Akademik Undang-undang Badan Hukum Pendidikan, h. 29-30).

\section{RUU BHP Usulan Pemerintah}

UU No. 20 tahun 2003 Pasal 53 Ayat (1) menetapkan "Penyelenggara dan/atau satuan pendidikan formal yang didirikan oleh Pemerintah dan masyarakat berbentuk badan hukum pendidikan." Ayat (4) menetapkan "Ketentuan tentang badan hukum pendidikan diatur dengan Undang-undang tersendiri". Selanjutnya Penjelasan Pasal 53 Ayat (1) menguraikan "Badan hukum pendidikan dimaksudkan sebagai landasan hukum bagi penyelenggara dan/atau satuan pendidikan, antara lain, berbentuk Badan Hukum Milik Negara (BHMN)". Dari ketetapan UU No. 20 tahun 2003 Pasal 53 Ayat (4) tersebut beserta Penjelasannya, serta keputusan Mahkamah Konstitusi sebagaimana tercantum dalam Risalah Sidang Mahkamah Konstitusi No. 021/PUU-IV/2006 tanggal 22 Februari 2007 agar undangundang mengenai badan hukum pendidikan yang diperintahkan oleh UU No. 20 tahun 2003 Pasal 53 Ayat (4) sesuai dengan UUD $1945^{\prime \prime}$, jelas sekali bahwa badan hukum pendidikan yang dimaksudkan adalah nama jenis dari badan hukum dari lembaga penyelenggaran dan satuan pendidikan formal. 
Kebijakan publik adalah tindakan yang dilakukan oleh Pemerintah secara langsung mau pun tidak langsung untuk mengatasi masalah yang dihadapi publik. Seperti diuraikan dalam Rencana Strategis Departemen Pendidikan Nasional, masalah pokok yang dihadapi oleh system pendidikan nasional adalah: (a) pemerataan akses kepada pendidikan bermutu; (b) kualitas dan reievansi,pendidikan; dan (c) efisiensi internal dalam pengelolaan penddiikan.

Tiga masalah tersebut terdapat pada semua jenjang pendidikan, tetapi kompleksitas intensitasnya dan keseriusan masalah mendasar pendidikan nasional yaitu, akses, mutu dan relevansi, serta efisiensi internal lebih menggejala pada jenjang pendidikan tinggi. Studi saya tentang Akses pada Layanan Publik menunjukkan sampai dengan 2003, hanya 4 persen penduduk dari Keluarga Kurang Mampu yang mendapat akses ke PT, sedangkan pada tingkat $S D$ akses telah mencapai 97 persen, SLTP dan SLTA lebih dari 52 persen. Mengingat salah satu kewajiban konstitusional Pemerintah adalah mencerdaskan kehidupan bangsa, serta memperhatikan kenyataan empiris tersebut, seharusnya yang menjadi sasaran dari RUU bhp adalah perguruan tinggi dengan tujuan utama membebaskan PTN dari belenggu birokratisasi instansi Pemerintah. Dengan demikian RUUBHP usulan Pemerintah yang bertujuan menyeragamkan badan hukum lembaga pendidikan formal menjadi satu Badan Hukum Pendidikan (nama diri) adalah bertentangan dengan kewajiban Pemerintah menurut UUD 1945, bersifat tidak demokratis dan a-historis karena akhirnya menafikan keberadaan yayasan, badan wakaf, persatuan, BLU dan BHMN, yang telah dikenal sebagai badan hukum pendidikan.
RUU BHP usulan Pemerintah bukan tawaran solusi terbaik untuk masalah keterbatasan akses Masyarakat Kurang Mampu pada pendidikan tinggi, mutu dan relevansi, dan rendahnya efisiensi internal Perguruan Tinggi, Sebaliknya, penyeragaman badan hokum pada semua jenjang pendidikan jelas akan menimbulkan komplikasi baru, komplikasi sosial-politik karena penyeragaman badan hukum penyelenggara pendidikan formal menjadi BHP, serta pemisahan badan hukum penyelenggaraan pendidikan formal (Yayasan, Badan Wakaf, dan bentuk badan hukum lainnya) dengan satuan pendidikan yang harus memilih badan hukum BHP, akan menimbulkan resistansi dan tantangan para penyelenggara pendidikan formal, antara lain ABPPTSI, APTISI, FRI serta dari kelompok masyarakat pendidikan lainnya.

Salah satu unsuryang diatur dalam RUU BHP usulan Pemerintah adalah perubahan status kepegawaian penyeleng-gara dan/atau satuan pendidikan dari PNS menjadi pegawai BHP (Non-PNS). Menurut data dari Badan Kepegawaian Negara (BKN), pada 2006 terdapat 3,7 juta PNS dan 1,7 juta di antaranya mempunyai pendidikan $D-1$ sampai dengan S-3 yang menduduki jabatan fungsional guru dan dosen. Perubahan status 1,7 PNS menjadi karyawan BHP akan menimbulkan implikasi sosial-politik yang amat besar dan diperkirakan akan menimbulkan gelombang protes yang mengandung resiko terganggunya stabilitas politik pada 2009. Di samping itu perlu diperhitungkan dampak perubahan PNS ke Karyawan BHP tersebut terhadap mutu aparatur Negara. Perubahan 1,7 juta PNS secara serentak akan berakibat $85 \%$ SDM aparatur Negara hanya memiliki pendidikan SLTAke bawah. Pada saat tuntutan pada aparaturNegara sangat tinggi, penurunan mutu SDM aparatur negara yang draștis seperti ini harus dihindarkan. 
Mengingatpertimbangan-pertimbangan seperti yang diuraikan dimuka, saya mengusulkan kepada Komisi X DPR-RI untuk menerapkan reformasi kelembagaan terbatas hanya pada penyelenggara dan/ atau satuan pendidikan tinggi, untuk meningkatkan otonomi dalam pengelolaan PT. Lembaga penyelenggara dan/atau satuan PT milik masyarakat sejak awal telah memiliki pengelolaan yang otonom, sehingga sukar dipahami apa alasan Pemerintah untuk mengubah badan hukum satuan pendidikan milik masyarakat menjadi BHP. Nampaknya, dalam pelaksanaan reformasi pendidikan nasional, Indonesia perlu belajar dari negara lain.

Seperti terbaca dari Outline UU Korporatisasi Jepang, Pemerintah Negara tersebut memfokuskan reformasi pendidikan hanya pada PT milik Negara dengan tujuan menciptakan manajemen PTN yang otonom dan menerapkan pendekatan manajemen korporat pada PTN. Belajar dari Jepang, saya mengusulkan kepada DPRRI dan Pemerintah untuk membatasi cakupan RUU BHP dan memfokuskan RUU BHP, dan memfokuskan reformasi kelembangaan hanya pada penyelenggara dan/ atau satuan pendidikan tinggi.

\section{Perpres No. 77 tahun 2007: Pintu Masuk Liberalisasi Pendidikan}

Setelah mengesahkan UU No. 25 tahun 2007 tentang Penanaman Modal, pada awal Juli 2007 Pemerintah Indonesia mengeluarkan 2 kebijakan pelaksanaan. Yang pertama Perpres No 76 tahun 2007 yang menetapkan kriteria dan persyaratan untuk bidang-bidang usaha yang tertutup dan terbuka untuk penanaman modal. Kedua, Perpres No 77 tahun 2007 yang menetapkan 25 bidang usaha yang tertutup dan 291 bidang yang. terbuka untuk penanaman modal dalam dan luar negeri dengan atau tanpa persyaratan. Di antara bidang-bidang usaha yang terbuka termasuk "bidang usaha" pendidikan yakni bidang usaha pendidikan dasar dan menengah, bidang usaha pendidikan tinggi, dan pendidikan pendidikan non-formal. Satu-satunya persyaratan yang ditetapkan kepemilikan modal oleh fihak luar terbatas sebesar 49 persen.

Dengan menerbitkan Perpres No. 77 tahun 2007, Pemerintah Indonesia secara sadar mau pun tidak telah merombak total paradigma pendidikan nasional. Pendidikan tidak lagi dipandang sebagai kewajiban konstitusional Pemerintah Negara untuk "mencerdaskan kehidupan bangsa" seperti diamanatkan dalam Pembukaan UUD 1945, termasuk menanamkan nilai-nilai luhur bangsa, semangat kebangsaan, rasa cinta tanah air, mengembangkan dan melestarikan budaya bangsa. Pendidikan secara blak-blakan telah ditetapkan sebagai bidang usaha atau bidang layanan jasa untuk meningkatkan ilmu pengetahuan dan ketrampilan yang diperiukan pasar.

Perubahan paradigmatis tersebut membawa 2 konsekuensi pada pengelolaan pendidikan nasional. Pertama, sebagai "bidang usaha" yang terbuka untuk penanaman modal luar negeri, walau pun dengan pembatasan modal luar negeri sebesar 49 persen. Kedua, lembaga penyedia layanan pendidikan formal dan pendidikan non-formal milik negara harus berbentuk badan hukum yang terpisah dari birokrasi pemerintah. Selanjutnya lembaga penyelenggara pendidikan formal milik masyarakat yang biasanya berbentuk yayasan, badan wakaf, persatuan perdata dan badan hukum sosial lainnya, walau pun telah puluhan dan ratusan tahun bergerak dalam bidang pendidikan formal dan non-formal, juga harus memisahkan satuan pendidikannya menjadi BHP. 
Perubahan paradigma pendidikan yang dilakukan oleh Pemerintah pastilah dipengaruhi oleh pandangan WTO tentang sektor industri atau usaha produktif. Sektor Primer adalah bidang-bidang usaha ekstraksi hasil tambang dan pertanian. Sektor Sekunder adalah semua bidang usaha pengolahan bahan dasar menjadi barang, bangunan, produk manufaktur dan barang yang diperlukan oleh publik (utilities). Sektor tersier adalah semua bidang usaha jasa untuk merubah wujud benda fisik (physical senvices), keadaan manusia (human services) dan benda simbolik (information and communication services). Sesuai dengan tipologi tersebut, WTO menetapkan pendidikan sebagai salah satu bidang usaha sektor tersier, karena kegiatan pokoknya ialah mentransformasi orang yang tidak berpengetahuan dan orang yang tidak berketrampilan menjadi orang berpengetahuan dan orang yang memiliki ketrampilan.

Kontribusi sektor tersier terhadap produk nasional suatu bangsa memang cenderung meningkat seiring dengan kemajuan pembangunan bangsa tersebut. Sejak $1980-$ an di negara-negara maju, perdagangan jasa tumbuh pesat dan telah memberikan sumbangan yang besar pada Produk Domestik Bruto (PDB), lebih besar dibandingkan dengan sektor primer dan sekunder. Tiga negara yang paling mendapatkan keuntungan besar dari liberalisasi jasa pendidikan adalah Amerika Serikat, Inggeris dan Australia (Enders dan Fulton, Eds., 2002, hlm. 104-105). Pada 2000 ekspor jasa pendidikan Amerika mencapai US \$ 14 milyar atau Rp. 126 trilyun. Di Inggeris sumbangan pendapatan dari ekspor jasa pendidikan mencapai sekitar 4 persen dari penerimaan sektor jasa negara ter-sebut. Menurut Millea (1998), sebuah publikasi rahasia berjudul $/ n$ telligent Exportsmengungkapkan pada 1994 sektor jasa telah menyumbangkan 70 persen pada PDB Australia, menyerap 80 persen tenaga kerja dan merupakan 20 persen dari ekspor total negara Kangguru. Sebuah survey yang diadakan pada 1993 menunjukkan industri jasa yang paling menonjol orientasi ekspornya adalah jasa komputasi, pendidikan dan pelatihan. Ekspor jasa pendidikan dan pelatihan tersebut telah menghasilkan AUS $\$ 1,2$ milyar pada 1993. Fakta tersebut dapat menjelaskan mengapa tiga negara maju tersebut amat getol menuntut liberalisasi sektor jasa pendidikan melalui WTO.

Sejak 1995 Indonesia telah menjadi anggota WTO dengan diratifikasinya semua perjanjian-perjanjian perdagangan multilateral menjadi UU No, 7 Tahun 1994. Perjanjian tersebut mengatur tata-perdagangan barang, jasa dan trade related intellectual property rights (TRIPS) atau hak atas kepemilikan intelektual yang terkait dengan perda-gangan. Dalam bidang jasa, yang masuk sebagai obyek pengaturan WTO adalah semua jasa kecuali "jasa nonkomersial atau tidak bersaing dengan penyedia jasa lainnya".

Sebagai negara yang memiliki 220 juta penduduk dengan tingkat partisipasi pendidikan tinggi hanya 14 persen dari jumlah penduduk usia 19-24 tahun, Indonesia menjadi incaran negara-negara eksportir jasa pendidikan dan pelatihan, karena pangsa pasar untuk pendidikan menengah dan tinggi sangat besar. Selain itu, sebagai konsekuensi dari rendahnya komitmen politik Pemerintah terhadap pendidikan, mutu akademis pendidikan nasional, mulai dari sekolah dasar sampai pendidikan tinggi, jauh di bawah standar mutu internasional. Kedua alasan itu lah nampaknya yang menjadi alasan Pemerintah untuk "mengundang" para penyedia jasa pendidikan dan pelatihan luar negeri yang berkantong tebal untuk datang membantu bangsa Indonesia. Guna melancarkan arus 
masuk modal jasa pendidikan tinggi dari negara-negara maju yang kaya, intervensi pemerintah dalam sektor jasa tersebut harus dihilangkan, karena regulasi pemerintah dipandang akan menghambat akses ke pasar sektor pendidikan. Liberalisasi semacam itulah yang hendak didorong melalui General Agreement on Trade in Services (GATS).

\section{Menghadapi Komodikasi dan Liberalisasi Pendidikan}

Globalisasi atau liberalisasi pendidikan tinggi yang sedang terjadi melalui jalur pasar bebas memang harus dihadapi dengan sangat hati-hati oleh negara-negara berkembang, tak terkecuali Indonesia. Implikasi jangka panjang dari globalisasi pendidikan tinggi tersebut belum sepenuhnya dapat di prakirakan, dan karena itu kebijakankebijakan antisipatif perlu dirancang dengan secermat mungkin agar globalisasi tersebut jangan sampai menghancurkan sektor pendidikan tinggi seperti yang terjadi dengan globalisasi sektor pertanian.

Agar dampak seperti tersebut di atas tidak terjadi, negara berkembang perlu merumuskan strategi yang paling tepat sebagai berikut: Meskipun konstelasi kekuasaan global yang ada saat ini tidak memungkinkan perguruan tinggi Indonesia, seperti halnya dengan banyak universitas di negara-negara lain, untuk merumuskan dan melaksanakan kebijakan-kebijakan yang kuat untuk menggoyahkan arsitektur kekuasaan global di bawah monopoli GATT/ WTO, namun dalam perspektif jangka panjang melalui pengembangan forum dan jaringan kerjasama regional dan internasional memiliki ruang yang cukup lebar untuk menghasilkan perubahan-perubahan yang berarti.
Reaksi masyarakat pendidikan tinggi terhadap masuknya pendidikan dalam GATS cukup luas. Assosiasi Perguruan Tinggi Amerika dan Kanada, Asosiasi Rektor Uni Eropah, Persatuan Naib Kanselor India, Majelis Rektor dan Perguruan Tinggi Indonesia secara terbuka telah menyampaikan himbauan kepada pemerintah masingmasing untuk meninjau pemberlakuan pendidikan tinggi sebagai komoditi yang diatur melalui GATS. Forum Rektor Indonesia yang mewakili 2300 perguruan tinggi dan lembaga swadaya masyarakat telah menginisiasi kerjasama antar universitas ( $d i$ tingkat nasional, regional dan internasional) untuk mendesak Pemerintah Indonesia agar mempertimbangkan kembali rencana WTO untuk memasukkan "pengetahuan" sebagai salah satu kategori "komoditi" ke dalam General Agreement on Trade in Services (GATS) yang ditandatangani pada bulan Mei tahun 2005. Bila langkah tersebut dilaksanakan dalam sinergi yang kokoh dengan kebijakan-kebijakan yang dilakukan oleh berbagai konsorsium universitas-universitas di Amerika Serikat, Kanada, Uni Eropa, India, dan Jaringan Universitas ASEAN, keberhasilan kebijakan yang dimaksud dapat diharapkan akan dapat mengikuti keberhasilan Forum Sosial Dunia dalam bidang pertanian.

Strategi kedua, dalam menyikapi globalisasi dan liberalisasi pendidikan tinggi, masyarakat pendidikan tinggi Indonesia, baik pemerintah mau pun masyarakat, harus mengambil sikap kritis. Di seluruh dunia memang sedang terjadi perkembangan, walau pun dengan kecepatan yang berbedabeda antar negara, menuju deregulasi pendidikan tinggi. Masyarakat sudah mulai harus diajak ke pemikiran yang lebih terbuka bahwa fungsi layanan pendidikan tinggi merupakan tanggung jawab bersama antara pemerintah, pemerintah daerah dan 
masyarakat. UU Sisdiknas sudah menganut paradigma seperti itu. Dengan demikian lembaga-lembaga swasta pun perlu diberi kesempatan yang besar dalam penyediaan layanan tersebut. Kesempatan yang sama perlu juga dibuka untuk lembaga pendidikan komersial dari luar negeri, tetapi dengan memperhatikan sekali kepentingan dan tujuan nasional. Secara ringkas dapat dikatakan bahwa liberalisasi pendidikan tinggi harus dilaksanakan oleh pemerintah Indonesia melalui langkah-langkah sebagai berikut:

- Liberalisasi dilaksanakan secara gradual (progressive liberalization), selektif, dan bertahap.

- Sesuai dengan tujuan kebijakan nasional

- Memperhatikan tingkat perkembangan setiap negara

- Memberikan fleksibilitas bagi negara berkembang

Strategi ketiga yang perlu ditempuh oleh Indonesia dalam menghadapi globalisasi pendidikan tinggi adalah melalui pendekatan jaminan mutu dan akreditasi sesuai standar internasional. UGM merupakan salah satu PTN yang secara serius mengembangkan program jaminan mutu dan menerapkan siklus penuh jaminan mutu. Kegiatan tersebut perlu dilanjutkan dengan program akreditisasi internasional terhadap program studi dan unit penyelenggara kegiatan pendidikan tinggi seperti jurusan dan bagian. Melalui program tersebut diharapkan pengakuan intemasional terhadap perguruan tinggi Indonesia akan semakin meningkat.

Strategi keempat yang perlu ditempuh oleh Indonesia adalah meningkatkan sistem akreditisasi nasional menjadi sistem akreditisasi regional dengan memanfaatkan jaringan perguruan tinggi regional, Asean University Network (AUN) dan Association of Southeast Asian Institute of Higher Leaming (ASAIHL) untuk mengembangkan sistem akreditisasi regional. Southeast Asia Ministry of Education Organization (SEAMEO) sebagai organisasi para menteri pendidikan adalah badan regional yang paling tepat untuk berfungsi sebagai kekuatan moral dan mempunyai legitimasi untuk mendorong program akreditasi regional tersebut. Apabila program akreditisasi regional dapat bejalan dengan baik, mungkin tidak terlalu sukar transisi ke program akreditasi internasional yang akan lebih memperbesar akses ke masyarakat internasional:

\section{Himbauan kepada Pemerintah}

Komunitas pendidikan nasional perlu menghimbau Pemerintah agar dalam melaksanakan UU No. 25 Tahun 2007 tentang Penanaman Modal, UU No. 7 tahun 1994 tentang ratifikasi perjanjian WTO, dan perjanjian-perjanjian multilateral, selalu memerhatikan dan mengutamakan kepentingan bangsa Indonesia dan tujuan nasional. Seperti diabadikan dalam Pembukaan UUD 1945 , para pemimpin bangsa dan pendiri Negara Republik Indonesia menyatakan bahwa salah satu tugas konstitusional Pemerintah Negara Indonesia adalah mencerdaskan kehidupan bangsa. Tugas konstitusional tersebut dilandasi pemikiran bahwa bangsa Indonesia telah menjadi korban kolonialisme dan imperialisme selama 350 tahun karena rendahnya tingkat pendidikan bangsa Indonesia.

Pendidikan nasional pada esensinya bukan bidang usaha jasa untuk menghasilkan tenaga kerja terdidik, yang satu kategori dengan industri pertambangan, perdagangan dan jasa. Pendidikan nasional adalah upaya Pemerintah dan semua unsur bangsa untuk to preserve national identity, to transfernorms and values, to sustain and 
develop the intellectual and cultural base of the society, to give inspiration and pride to citizens, dan to promote dialoge for the respect of cultural and social diversity.

Salah satu tugas utama pendidikan nasional, terutama pendidikan dasar dan menengah, adalah mentransfer nilai-nilai luhur bangsa, menanamkan semangat kebangsaan, menanamkan identities bangsa, dan melestarikan serta mengembangkan budaya bangsa. Tugas mulia tersebut adalah tugas Pemerintah dan merupakan tanggung-jawab bangsa Indonesia sehingga tidak mungkin dialihkan menjadi tanggungjawab para pemilik modal usaha jasa pendidikan. Liberalisasi jasa pendidikan tinggi dan sub-sektor pendidikan lainnya haruslah dilaksanakan dengan sikap nasionalisme yang kuat, dilakukan secara bertahap dan dengan memperhitungkan kesiapan nasional kita untuk mengembangkan hubungan yang simetris dengan lembaga pendidikan tinggi negara lain. Tanpa kesiapan nasional tersebut, dikhawatirkan sektor pendidikan kita kembali akan menjadi korban dari hubungan assimetris atau persaingan yang tidak seimbang antara pemain lokal dengan para penyedia layanan pendidikan dari luar negeri. Jangan dilupakan bahwa globalisasi pendidikan membawa bersamanya illicit effects seperti maraknya operasi penjual ijazah, pendirian sekolah oleh kelompok-kelompok yang bertentangan dengan kepentingan nasional, serta kegiatan-kegiatan negatif dalam bidang pendidikan.

Komunitas pendidikan nasional (asosiasi perguruan tinggi, sekolah/ madrasah, asosiasi dosen dan guru, asosiasi penddidikan pada umumnya) yang masih memegang teguh semangat nasionalisme pendidikan perlu mengingatkan DPR-RI dan Presiden untuk tidak terlalu bersemangat mengobral jasa pendidikan dan menjadikannya lahan subur untuk dilahap oleh negara-negara maju bermodal besar dan memiliki sumberdaya lebih baik.

\section{Daftar Pustaka}

ASEAN Secretariat, 1995. ASEAN Framework agreement on services. Jakarta. Asean Secretariat.

De Groof, Jan, Gracienne Lauvers, dan Germain Dondelinger. 2003. Globalization and Competition in Education. Nijmegen. The Netherlands. Wolf Legal Publishers.

Departemen Pendidikan Nasional. 2005. Rencana Strategi 2004-2009. Jakarta. Depdiknas.

Enders, Jurgen dan Oliver Fulton. Eds., 2002. Higher Education in a Globalizing World. Dordrecht. Kluwer Academic Publishers.

ILO. "life-long learning in the Twenty-first Century: The changing role of educational personnel". Report for the discussion at the Joint Meeting on Lifelong Leaming in the Twenty-first Century. (www.ilo.org/public/english/dialogue).

Sekretariat Negara R.l., UUD Negara Republik Indonesia Tahun 1945.

Presiden No. 77 Tahun 2007.

"The Brain Industry". The Economist, September 10, 2005.

Warouw, Adolf. "Liberälisasi Jasa Pendidikan dalam Kerangka WTO". Presentasi pada Diskusi Liberalisasi Jasa 
Pendidikan. Diselenggarakan oleh Departemen Perdagangan. Jakarta.

Webster, Frank. 2002. Theories of the Information Society. New York, NY.: Routledge.

Van Glinken, Hans. 2004. "Globalization. Higher Education and Sustainable
Development". Paper at First Asean

- European Union Rectors' Conference. Organized by the Ministry of Higher Education of Malaysia, University of Malaya. Delegation of the European Commission in Malaysia, andAsean-European Union Network Programme. Kuala Lumpur, October 4-6, 2004. 